\title{
El Cuaderno de Condiciones del Común de Guadalajara de 1405
}

\author{
JOSE-Miguel LOPEZ VILLALBA
}

En la historia del régimen local español la única transformación de trascendencia comparable a la actual es el paso, en los últimos siglos medievales, del Concejo abierto al Concejo cerrado o Regimiento. En este estudio trataremos algunos aspectos de aquel gran cambio ${ }^{1}$.

Las líneas generales del proceso son conocidas: hubo una época de autogobierno municipal, que tuvo su inicio en el siglo XI con las primeras concesiones de los reyes, obligados por las necesidades de la reconquista y repoblación, a los concejos, que culminó a mediados del siglo XIII, y que coincidió con la forma de gobierno que llamamos Concejo abierto, o asamblea de todos los vecinos. Hubo después una reacción real, que impuso una junta de regidores en algunas ciudades como Burgos (1343), Segovia (1345) y Madrid (1346), y que completó Alfonso XI en el Ordenamiento de Alcalá de 1348, sustituyendo al Concejo abierto y abriendo camino de este modo para que las minorías oligárquicas de las ciudades monopolizaran el gobierno local.

¿De la democracia a la aristocracia? No, desde luego. En esas líneas generales que hemos indicado caben algunas aclaraciones. No es la menor reparar en que el Concejo abierto nunca fue una asamblea democrática y en que antes del Regimiento el gobierno local ya era cosa de una parte privilegiada de los vecinos y no de todos, de modo que la intervención legislativa de Alfonso XI no significó una ruptura sino una

“Dicha reforma sería la de más trascendencia en la historia del régimen municipal español». R. GIBERT, El Concejo de Madrid. Su organización en los siglos XII al XV. Madrid 1949, pág. 123. 
adaptación de las formas legales a la práctica. Según Valdeón, la reforma de Alfonso XI fue "la aplicación de reglas claras en un proceso que conducia inevitablemente a la consolidación del gobierno municipal en manos de las oligarquías urbanas".

\section{PROPÓSITO DE ESTE ESTUDIO}

Nos ha movido a la redacción de este trabajo la lectura de unas ordenanzas $^{2}$ de gobierno para la villa de Guadalajara de 1405 . Ello, por dos motivos:

El primero, porque hay razones para creer que en esta fecha de 1405 y con tales ordenanzas se estableció el sistema de Regimiento en Guadalajara.

El segundo, porque fue el común de la villa de Guadalajara quien compuso aquellas ordenanzas y, con el nombre de condiciones, las presentó a la clase de caballeros y escuderos para que se comprometieran a cumplirlas mediante juramento; de modo que, por lo que sabemos, contra lo que cabría esperar, la instauración del Regimiento en la villa de Guadalajara o, mejor dicho, las decisiones acerca de su composición y funcionamiento fueron, en principio, obra del común y no de la oligarquía ${ }^{3}$.

Nuestro proposito es fijar la tradición documental de las mencionadas ordenanzas de 1405, explicar cuál fue su génesis y analizar su contenido. Finalmente incluimos una transcripción de su versión más antigua.

\section{LA FUENTE DOCUMENTAL Y SU TRADICIÓN}

No se conserva el original de 1405 , ni el original del acta de la asamblea del común, en la cual, ese mismo año, el 28 de octubre, los

2 Un buen estudio general para las ordenanzas municipales del reino castellano-leonés, es el de E. Corral Garcia, Las ordenanzas de los concejos castellanos. Formación, contenido y manifestación (siglos XIII-XVIII). Madrid, Instituto Estudios Admón. Local, 1982.

3 "Las ordenanzas, por su origen, pueden ser reales, señoriales, de los concejos y gremiales", Corral Garcia, obra citada, págs. 94-95. 
hombres buenos pecheros, cuatros y sexmeros juraron cumplir las nuevas ordenanzas si los caballeros y escuderos hacian lo mismo. Si conservamos dos copias de dicha acta en el Archivo Municipal de Guadalajara, una muy cercana al original, de 1417, otra de 1545. Con más detalle, bajo las letras A), B), C) y D) describimos a continuación esas etapas de la tradición documental.

A) 1405. Guadalajara.-Carta por los "quatros" y hombres buenos pecheros de las collaciones, en nombre del común, a los caballeros y escuderos, a quienes piden que cumplan ciertas condiciones en materia de gobierno. - Perdida.

B) 1405, octubre, 28. Guadalajara, en la Iglesia de San Gil.-Acta, por Juan Sánchez de Coca, escribano, del juramento dado por el común, hombres buenos pecheros, "quatros" y sexmeros, de cumplir las condiciones, presentadas por el procurador del común, Juan Martínez, contenidas en la fuente A), con la condición de que los caballeros y escuderos jurasen lo mismo.--Perdida.

C) 1417, septiembre, 10. Guadalajara.- Traslado acta de la fuente B) por orden de Gutier Núñez, alcalde, realizado por Pero Ferrández, escribano, a petición de Sancho Díaz de Cortinas, Ruy Ximénez Cherino y Juan de Encinas.-Se conserva en el Archivo Municipal de Guadalajara, en muy mal estado, con la signatura $1 \mathrm{H} 3.8 \mathrm{a}$. Son cuatro hojas de papel de $305 \times 232 \mathrm{~mm}$.

D) 1545. Guadalajara.-Copia, por Juan de Santamaría, escribano de la fuente C). - Incluida en el llamado Libro copiador de ordenanzas y escrituras, que guarda el Archivo Municipal de Guadalajara, con la signatura 1 H52.1.

Una transcripción de la fuente D) fue publicada por el cronista de Guadalajara Francisco Layna Serrano ${ }^{4}$. Esa transcripción, la única que existe, contiene algunos errores de lectura e, inevitablemente, reproduce los errores que ya cometía esa misma fuente D) de 1545, con respecto a la fuente C) de 1417, que Layna Serrano no cotejó.

Entre esos errores hay algunos de poca importancia (algunos lapsus transcriptorios), como la exclusión de alguna frase no relevante. Donde Layna Serrano transcribe: “... segund que lo han de uso y de costunbre de se ayuntar e estando y presentes Diego Ferrández, fijo de Benito

4 F. Layna Serrano, Historia de Guadalajara y sus Mendoza en los siglos xV y XVI. Madrid, C.S.I.C. Instituto "Jerónimo Zurita» 1942, t. II, págs. 519 a 522. 
García"; deberia haber transcrito: "segund que lo han de uso e de costunbre de se ayuntar e estando y presentes Diego Ferrández de Hita, texedor, quatro de la collación de Santiago, e Diego García, fijo de Benito Garcia". Hay también en dichas transcripciones dos errores que es preciso rectificar. El primero, que ya figura en la copia de 1545, afecta a la data del cuaderno de condiciones. En dicha copia y en la transcripción publicada por Layna Serrano se lee "1406", donde en la fuente C) de 1417 dice claramente «1405». El segundo error, sólo en la transcripción, es una abreviatura no desarrollada. Los caballeros y escuderos de Guadalajara estaban obligados a guardar una sentencia dictada por el Almirante Diego Hurtado de Mendoza. En las fuentes C) y D) la palabra "sentencia" figura abreviada como "senya", que inexplicablemente Layna Serrano dejó sin desarrollar. El hecho no tendría importancia si no fuera porque otros autores, que han utilizado la transcripción de Layna, han perdido el sentido del texto al no entender qué era realmente la "senya" del Almirante ${ }^{5}$.

Por nuestra parte, presentamos aquí la transcripción de la fuente $\mathrm{C}$ ), la más antigua conservada. Puesto que se halla en muy mal estado, con partes perdidas al final de la mayor parte de las hojas y en los bordes, hemos suplido esas pérdidas acudiendo a la fuente D).

\section{BIBLIOGRAFIA}

Un extenso número de ordenanzas medievales han visto la luz publicadas sobre todo en revistas de historia del Derecho y de Administración Local, como el prestigioso Anuario de Historia del Derecho Español (AHDE). No menos numerosos son los trabajos que en mayor o menor medida se fundamentan en las noticias aportadas por los ordenamientos locales.

5 Caroline Mignor en su artículo "Le "Municipio" de Guadalajara au Xveme siècle, système administratif et économique (1341-1567)", publicado en Anuario de Estudios Medievales, núm. 14, pág. 587, nos dice: "En outre, les "ordenanzas" de 1406, fon reférence au droit d'intervention des marquis dans la désignation des offices, "la senya del almirante", qui découle de leurs pouvoirs juridictionnels". Como vemos en este párrafo reproduce dicha autora los dos errores citados. 
Tanto medievalistas como historiadores del Derecho han tratado de las ordenanzas; destacamos, entre otros, a Emilio Sáez ${ }^{6}$, José María Lacarra ${ }^{7}$, Monsalvo Antón ${ }^{8}$, Miguel Ángel Ladero Quesada, Pérez Prendes o Garcia-Gailo.

Una magnifica relación bibliográfica es la que nos ofrecen Pérez Prendes, en su Curso de Historia del Derecho Español, págs. 556 a 563 y 564 a 675 (en notas a pie de página). Volumen I, Sección de Publicaciones. Facultad de Derecho. Universidad Complutense. Madrid 1984, y Ladero Quesada, M. A., y Galán Parra, I., en su artículo "Las ordenanzas locales en la Corona de Castilla como fuente histórica y tema de investigación (siglos XIII al XVIII)", págs. 221 a 243 (en notas a pie de página), AVA 1982. Por lo tanto, obviamos reproducirlas, y ante lo exhaustivo de las mismas nos remitiremos a citar en notas algunos de los trabajos consultados.

\section{GENESIS DOCUMENTAL}

En este apartado consignamos los hechos deducidos de la simple lectura de la fuente, entre ellos:

- Instauración del Regimiento en la villa de Guadalajara.

- Composición de la Asamblea del común.

- Conflicto entre común y baja nobleza.

- El juramento como instrumento de ratificación.

- Información acerca del número y nombre de los integrantes de la clase de caballeros y escuderos.

No podemos afirmar rotundamente que la creación del Regimiento en Guadalajara se produjo con motivo de la aceptación por parte de los nobles del cuaderno de condiciones que les presentaron los pecheros y cuya primera condición habla del Regimiento. Pero en dicho cuaderno no

${ }^{6}$ E. Sázz, Ordenanza del Concejo de Santa María de Olzo, Zarzosa, Corral de Yuso y Villarejo de la Serna (1516). AHDE 21.

7 J. M. LACARRA, Ordenanzas municipales de Estella. AHDE 5.

B J. M. MONSALVO ANTON se encuentra estudiando actualmente las ordenanzas de Ávila. 
aparece ninguna mención de la existencia de regidores antiguos y es enormemente significativo el título que en el traslado de 1417 (fuente C) se dio a dichas condiciones: "Ordenanças de la villa del tiempo que no avia regidores en ella". Esta anotación, escrita en la cabecera del primer folio recto del documento, en letra cortesana pero de distinta mano del escribano Pero Ferrández, es probablemente posterior al traslado de las mismas de 1417. Mas eso mismo hace relevante dicha anotación; alguien quiso situarlas en el tiempo y para ello recurrió a un hecho conocido: que antes de aquellas ordenanzas no había regidores.

La exposición comienza indicando que el día 28 de octubre de 1405 se reunieron en asamblea en la iglesia de San Gil el común, hombres buenos pecheros, quatros y sexmeros de la villa de Guadalajara.

Diferencia el documento una asamblea integrada por cuatro grupos de pecheros.

El común, como conjunto englobador de los moradores poco relevantes, aquellos cuyo único medio de subsistencia son sus propios brazos. Deseariamos antes de continuar hacer una observación acerca de la voz común, como concepto de unidad social, algo problemático en cuanto es difícil de discernir hasta qué punto sólo representa al pueblo llano y no a otros moradores del lugar entre los que se insertarian las minorias marginadas.

Los hombres buenos pecheros, o "boni homines", son los plebeyos destacados del lugar, artesanos, comerciantes o propietarios que han logrado una privilegiada situación respecto a la Asamblea ${ }^{9}$.

Los "quatro", representantes de las collaciones o barrios. Las collaciones de Guadalajara eran: Santiago, San Gil, San Nicolás y Santa María, y sus representantes respectivos, en 1405, Diego Ferrández de Hita, Diego García, Gonzalo Ferrández y Pero Ferrández.

Los sexmeros, como representantes del alfoz de la villa. En esta ocasión estuvieron presentes: Lucas Martínez, por el sexmo de Albolleque; Juan Martínez del Exido, delegado del de Valdeavellano; Diego Ferrández, del de Taraçena, y Diego Ferrández de Sillas, por el de Málaga.

Una vez reunidos, el procurador del común, Juan Martínez, hizo leer a! escribano público, Juan Sánchez de Coca, un cuaderno de nueve con-

9 "La asamblea quedó reducida, primero de hecho y luego de derecho, a un concejo reducido de "caballeros y hombres buenos" en la Baja Edad Media". CorRal Garcia, obra citata, pág. 15. 
diciones en el que trataban de los oficios concejiles, cuyo autor probablemente fuera una comisión nombrada por el común, y por el cual piden a caballeros y escuderos que las cumplan: «... vos pedimos que nos guardedes e fagades guardar e conplir para que todos seamos concordados e amigos conjuntamente con vosotros en rrazón de los oficios".

La razón de esta solicitud a la nobleza estaba en la finalización de unas rencillas anteriores que habian tenido ambos grupos sociales. $\mathrm{Si}$ caballeros y escuderos aceptaban, los autores del cuaderno estaban de acuerdo en que éstos tuvieran los oficios municipales como siempre los habian tenido.

Las condiciones debian ser aceptadas con un juramento delante de escribano público. Dicho juramento tenia un doble significado: civil y religioso. Primero, obligaban sus bienes, y segundo, bajo la pena de perjuro, juraban por la señal de la Cruz y los Santos Evangelios.

Finalizado el acto de lectura, todos los reunidos entregaron al procurador Juan Martínez un poder que le facilitase la obtención de los juramentos, para que posteriormente, con toda la documentación en regla, fuese a ver al rey Enrique III y obtuviese la confirmación real de todos estos oficios para la villa de Guadalajara. Juan Martínez recibió el poder obligándose con sus bienes al cumplimiento de lo dispuesto en él.

Finalmente, los "quatros" y sexmeros pidieron que quedase testimonio firmado por escribano público de todo el sumario de juramentos por parte de la nobleza y de todo cuanto éstos fuesen haciendo y respondiendo. Demostraban con esta petición la importancia que daban a dicho proceso de aceptaciones.

Este proceso comenzó al día siguiente, 29 de octubre de 1405. El procurador Juan Martínez y el escribano Juan Sánchez de Coca se trasladaron a la aldea de Centenera de Yuso, en las afueras de Guadalajara, donde se reunieron con el Concejo y hombres buenos de la misma en la iglesia del lugar. Alli les fue leído a los convocados el cuaderno de condiciones y éstos otorgaron al procurador un poder igual al que le había dado la asamblea de Guadalajara.

Más tarde, en el mismo día, se reunieron a campana repicada, en la cámara del Concejo de Guadalajara, el Concejo, caballeros, escuderos y hombres buenos de la villa. Siguiendo el ritual preestablecido, el escribano leyó el cuaderno y posteriormente Juan Martínez se dirigió a los caballeros y escuderos que estaban presentes pidiéndoles que cumplieran las ordenanzas contenidas en dicho cuaderno. 
Contestaron aquéllos que les parecia bien y que juraban lo leído obligándose con sus bienes. Esta primera parte del ceremonial acarreaba un doble gravamen: pecuniario, con pena de 2.000 maravedís, y moral, dando su palabra de caballero.

La segunda parte estaba marcada por el carácter religioso de las formas, en el cual caballeros y escuderos juraban las condiciones por la señal de la Cruz mientras tomaban los Santos Evangelios con las manos, comprometiéndose bajo la pena de perjuro, según podemos ver en el apéndice documental núm. II: «... e por mayor abondamiento de derecho fizieron juramento por la señal de la Cruz e las palabras de los Santos Evangelio que tanxeron... so pena de perjuros".

El proceso de los juramentos duró desde el 29 de octubre hasta el 4 de diciembre de 1405.

Puesto que buscaban los juramentos de todos los caballeros y escuderos hemos relacionado exhaustivamente los nombres de los que juraron, consiguiendo una visión de la oligarquía urbana de Guadalajara a comienzos del siglo xV.

\section{CABALLEROS Y ESCUDEROS SIN ESPECIFICAR}

García López, hijo de Garcia López de Trillo.

Lope García de Salazar.

Ferrando Mexía.

Ruy Lorenço, hijo de Lorenço Sánchez.

Juan Gastón, hijo de Ferrando Gastón.

Ferrando López de Horozco.

Ferrando Páez de Çorita.

Garcia López, hijo de Lorenço Ruiz de Trillo.

Sancho, hijo de Sancho Ferrández, el tío.

Ruy Sánchez de Horozco.

Martín Ruiz de Benegas.

Diego López de San Pedro.

Diego González de Garijo. 
Juan Hortuñas de Padilla.

Ferrando Juste de Loaysa.

Juan de Ochoa.

Garcia López, hijo de Pedro García de Trillo.

Lope Sánchez de Lasarte.

Ferrando Alfonso de Castro.

Martín Rodriguez.

Sancho Díaz de Cortinas.

Ferrando Sánchez de Horozco.

Caballeros

İnigo López de Valdés.

Ferrando Páez.

Martín Alfonso de Torre.

Sancho Ferrández del Arco.

Escuderos

Juan Ferrández de la Fuente.

García Díaz de Hita.

Juan Ferrández, hijo de Juan Ferrández.

Pero López.

Alfonso Ferrández, hijo de Antón Martínez.

Pero Ferrández, hijo de Diego Ferrández.

Sancho Sánchez de Horozco, hijo de Sancho Sánchez.

Ruy Ferrández de Açequella.

Diego, hijo de Nuño Ferrández.

García González, hijo de Alfonso Gutierrez de Tórtola. 
Pero Páez, hijo de Ferrando Páez.

Ruy Ximénez Cherino.

Diego Ferrández de la Fuente.

Pero Ruiz, hijo de Martín Alfonso de Torre.

Ferrando Díaz.

Gonçalo Ferrández, hijo de Juan Ferrández.

García, hijo de Ferrando Páez.

García López, el mozo, hijo de Garcia López de Trillo.

Ferrando Sánchez, hijo de Sancho Ferrández del Arco.

Alfonso Diaz, hijo de Gutierre Díaz.

Gonçalo Ferrández, hijo de Gonçalo Martinez.

Diego Gómez de Sandoval.

Juan Alvarez.

Sancho García.

Lope Martinez de Quintas.

Sancho, hijo de Sancho Ferrández del Arco.

Garci López de Castilnovo.

Dentro de este proceso, el día 3 de noviembre se presentó en Guadalajara, el sexmero de Lupiana, Martín Ferrández, que en nombre de su sexmo entregó a Juan Martínez como procurador del común, un poder similar a los ya otorgados.

\section{EL CONTENIDO DEL DOCUMENTO}

El documento se presenta dividido en una introducción y nueve condiciones que hemos numerado del I al IX en el Apéndice Documental núm. I que figura al final del trabajo.

El conflicto que sirve de incentivo a este cuaderno de condiciones estuvo latente al redactar la introducción, que hace un llamamiento a la concordia entre los diversos grupos sociales. 
En las siguientes líneas enmarcaremos este enfrentamiento en los conflictos sociales desarrollados a raiz de la llegada a la monarquía de la dinastía Trastámara, que convulsionaron las relaciones nobleza-pueblo. Dentro de esta serie de disputas destacan las noticias de las Cortes de Valladolid, de 1385, donde los representantes de las ciudades elevan a Juan I, rey de Castilla, una queja por los agravios cometidos por los señores de villas y ciudades. La repetición de las quejas en Segovia durante el año 1386 nos hace suponer una situación generalizada en Castilla ${ }^{10}$, de la que Guadalajara no había de ser una excepción, según nos trasmiten fray Hernando Pecha ${ }^{11}$ y Layna Serrano ${ }^{12}$ en sus obras.

Estas fuentes nos dicen que el Concejo de Guadalajara para terminar con las disensiones entre nobleza y común ofreció en 1395 al Almirante don Diego Hurtado de Mendoza, representante de los Mendoza, la facultad hereditaria ${ }^{13}$ de nombrar todos los oficios concejiles.

Siguiendo a Hernando Pecha en su relato sobre la elección de oficiales municipales en tiempos del Almirante don Diego Hurtado vemos cómo todos los años el día de San Miguel se reunian en el pórtico de la iglesia de San Gil nobles y pecheros. El escribano preguntaba a los convocados qué se hacía con los oficios del Concejo, a esto respondía el procurador general que para evitar rencillas entre los habitantes de la ciudad se entregaran al Almirante. Tras ser aceptado este parecer, continuaba el ceremonial con la lectura de los elegidos por parte de un secretario del Almirante. Poco después todos juntos marchaban a casa de don Diego Hurtado que les exhortaba sobre el buen cumplimiento de sus oficios, y posteriormente iban al Concejo donde tomaban posesión de los cargos.

En vida del Almirante se realizaron con asiduidad estas elecciones, como corroboran noticias posteriores con motivo de la expedición que realizó don Diego, como Almirante de Castilla, contra los berberiscos en el año 1400. Los oficiales locales incumplieron con su ejercicio de poder y las afrentas llegaron hasta la administración real. El rey Enrique III se

${ }_{10}$ Un estudio indispensable y revelador para la historia de los movimientos sociales es el de J. ValdeON BaruQue. Los conflictos sociales en el reino de Castilla en los siglos XIV $y \times V$.

Fray Hermano PECha, Historia de Guadalaxara, 1652.

12 F. Layna SerRano, obra citada, 4 tomos.

13 Caroline Mignot, en su art. cit., pág. 586, nos delimita los oficios que nombraban los descendientes del Almirante: "Le marquis ne reçoit explicitement confirmation que des charges de notaire, officier censeur et juge d'appel en 1444 ". 
vio obligado a nombrar y enviar un corregidor, en la figura de micer Ventura Garzón, para que aclarase la situación ${ }^{14}$.

Vuelto el Almirante, y enterado de los acontecimientos que se habian desarrollado en su ausencia en Guadalajara, marchó al encuentro del rey, que se encontraba en la ciudad de Segovia, y alli consiguió que se le devolvieran todos los derechos por escritura de 16 de noviembre de 1401.

Con la muerte de Hurtado de Mendoza, en 1404, se abrió un nuevo periódo, del cual bien pudiera ser el primer paso las condiciones que el común presentó al año siguiente y por medio del cual el grupo social dominado intenta un acercamiento al poder local, aun aceptando desde las primeras líneas del documento la preponderancia de la nobleza, confirmándonos que existía una convicción clara de la división de la sociedad en diversos grupos.

La alta nobleza, siempre en un status superior, más preocupada por su situación en la Corte y la alta política que por las minucias locales. Está representada en la villa por los Mendoza, y sus ramas colaterales, principalmente ${ }^{15}$.

Los caballeros y escuderos, que forman la baja nobleza, dedicándose en su mayor parte a la ganaderia con diversa fortuna. Mientras algunos vivian con unas rentas saneadas, otros muchos tenidos por hidalgos apenas poseían el título ${ }^{16}$, mas su situación legal les libraba de los impuestos y les otorgaba una categoría elevada en la sociedad local, les hacía vivir con una prepotencia alejada en bastantes ocasiones de su verdadera fortuna. Otros menos afortunados aún no podian ni mantener los signos externos de la caballería de alarde.

Los plebeyos vivían de la actividad económica agrícola, del artesanado o del comercio, bien como propietarios o como asalariados. Bastantes habian logrado poseer viñas y huertas en las tierras que rodeaban a la villa, lo cual les permitía tener una cierta relevancia en la sociedad

14 AHN. Casa de Osuna, legajo 1875. Publicado por F. Layna Serrano, en obra citada, tomo I, pág. 302.

15 "Tan ligadas están las historias de Guadalajara y de la ilustre casa de Mendoza, que resulta imposible estudiarlas por separado". F. Layna Serrano, obra citada, tomo I. Prólogo, pág. 7.

${ }_{16}$ «Ora llamados exprofeso y otras veces por propia voluntad, fueron acudiendo a Guadalajara, numerosos hidalgos más ricos en pergaminos que en bienes. LAYNA SERRANo, obra citada, tomo I, pág. 116. 
local. En el Cuaderno de Condiciones se denominan a ellos mismos como «labradores».

Por último habia un grupo social heterogéneo compuesto por las minorias marginadas, tanto económicas como sociales o religiosas, las cuales no influian para nada en la política local.

El estudio de las nueve condiciones lo haremos siguiendo los oficios concejiles que se regulan en las mismas.

\section{REGIDORES}

Los regidores acapararon las principales funciones de poder y administración de la vida municipal bajomedieval. No difirieron mucho sus funciones en la villa de Guadalajara del resto del reino castellano-leonés: gobernar la villa y administrar la hacienda de la misma, ayudándose para esto último de los mayordomos a los cuales nombraban.

En Guadalajara llegaron al poder como consecuencia de una nefasta administración anterior que llevó a la vecindad de pecheros a demandar la presencia de estos oficiales como respuesta a tanta degradación. Solución que con el tiempo resultará un arma de doble filo al ser los oficios de regidores vitalicios y llegar a una patrimonialización que los hizo caer en manos de la oligarquía urbana ${ }^{17}$.

Pero los pecheros de Guadalajara no pensaba en un futuro lejano cuando solicitaron por medio de la primera condición que se escogieran ocho regidores para gobernar la villa, seis elegidos entre los nobles y dos entre los pecheros, sino en censurar la vida local evitando más afrentas de los diversos alcaldes y alguaciles que habian campado por sus respetos hasta entonces. Por eso solicitaron a los regidores que lo primero que debian hacer tras tomar las riendas del poder local era reparar los agravios realizados por los antiguos oficiales.

17 "Como consecuencia del carácter vitalicio y la creciente tendencia a considerario hereditario va a originar el inicio de la patrimonialización de tales oficios". C. MERCHAN FERnÁndez, El gobierno municipal en Extremadura en la Baja Edad Media. Cáceres, Ediciones de la Universidad de Extremadura, 1984. 
La jurisdicción de los regidores no quedaba en esta primera condición suficientemente explicada lo que motivó posteriores injerencias que obligó a legislar sobre las competencias de regidores en las Ordenanzas de 1427 en los artículos I, III, IV y XII. Se insistía sobre ello, ya que la falta de limitaciones les llevó a traspasar barreras de jurisdicciones, tales como el ejercicio del poder judicial, y se entrometian en las labores de alcaldes, jurados y alguaciles.

El salario de los regidores en 1405 era de 4.000 maravedís anuales, renta bastante elevada para la época, que poco debió durar, pues en 1427, por medio de la ordenanza VI, se les asignaba un sueldo de mil maravediés.

\section{MAYORDOMOS}

El mayordomo es el responsable de la economía del Concejo, estando toda la hacienda municipal en sus manos. En este sentido, los mayordomos son meros ejecutores de las órdenes emanadas desde la institución del Regimiento que los nombra para ello.

Por esto mismo, los mayordomos han de poseer bienes económicos en cuantía suficiente para responder de sus actos en la inspección anual que realizaban delante de regidores y "quatros" unidos en cabildo para revisar el correcto desempeño de la funciones recaudatorias que los primeros tienen asignadas.

Los regidores estaban muy interesados por la adecuada gestión de los mayordomos al frente de la hacienda por ser ellos y sus bienes los responsables últimos de la hacienda concejil.

Entre ias diversas actuaciones de los mayordomos están especificadas en la primera condición las referentes a recaudación y administración de los bienes de propios del Concejo.

Los propios del Concejo se habían creado para el mantenimiento de la muralla ${ }^{18}$ y sólo podian usarse para ello excepto si el rey mandaba

18 "Guadalajara, importante ciudad de Al-Andalus, habia visto crecer un alcázar, y posteriormente en el siglo $x$ una muralla, que el paso del tiempo no respeto. Alfonso VIII dio el empujón definitivo para la construcción de una nueva muralla. En el siglo xvi todavía se mantenia en buenas condiciones". A. HERRERA CASADO, "La muralla de Guadalajara", Revista Wad-al-Hayara, núm. 13. Guadalajara 1986, pág. 421. 
una carta indicando lo contrario. Cuando estas rentas no se empleaban adecuadamente, tal y como habia venido sucediendo, se obligaba a los labradores (terminología usual en la época para definir al común) a realizar el trabajo de reparación gratuitamente, con los perjuicios que esa situación injusta les acarreaba en cuanto a pérdida de dias de trabajo ${ }^{19}$.

Entre los propios del Concejo destacaban los terrenos del campo y la alcarria. El campo eran las fértiles tierras próximas a las riberas del rio Henares, y la alcarria eran los montes que flaquean la villa por el Este. Sus principales beneficios provenian de la venta de leña y el arrendamiento de los pastos para el ganado.

\section{ALCALDES ORDINARIOS}

De los alcaldes ordinarios trata la segunda condición del cuaderno.

Durante el siglo XIV los alcaldes ordinarios tuvieron una importancia crucial en el Concejo de Guadalajara que al llegar el Regimiento decaerá por pérdida de competencias.

Elegidos por suertes, los preseleccionados deberían ser de la villa, "contiosos" y ser hombres piadosos. Vemos pues, cómo para ejercer el cargo de alcalde había que ser "contioso" o "caballero quantioso", 10 que lleva parejo el mantenimiento de caballos, armas y arneses para la inspección anual. Ya desde tiempo de Alfonso IX (1198-1230) era condición sine qua non la posesión de al menos un caballo para ejercer de alcalde.

Los elegidos, en número de cuatro, juraban el cargo por un año en la iglesia de San Gil, lugar habitual de los actos comunales, en un acto presidido por el cabildo de regidores y "quatros".

Noticias posteriores nos confirman que los cuatro alcaldes elegidos tenían igual jurisdicción ${ }^{20}$. Cada uno de ellos ad praeventionem, por lo que los vecinos podian acudir libremente al que deseaban solucionase

19 "La mala calidad del material de construcción en la zona hizo que se realizase a base de sillarejo calizo e hiladas de mampuesto y ladrillo" A. HERRERA CASADO, obra citada, pág. 430.

${ }^{20}$ Hernando PECHA, obra citada, pág. 94. 
sus querellas, sin que ninguno de los otros alcaldes pudiese entrometerse en dicha causa.

\section{ALGUACIL}

La tercera condición habla de las funciones del alguacil y sus hombres.

La figura del alguacil del Concejo de Guadalajara se corresponde con la del alguacil mayor en la mayoría de los municipios castellanosleoneses en la Baja Edad Media.

Nombraba este oficial a su lugarteniente y a todos los hombres que le ayudaban. Una vez designados, debia dar relación de los mismos a los regidores de la villa para su posterior control pues las circunstancias habían llevado a exigir al común por medio de esta tercera condición que sólo una minoría vigilada llevase armas y con el único fin de defender la villa. Estos hombres del alguacil tuvieron entre otras funciones: perseguir delicuentes y prenderlos y tomar prendas a los hallados en falta.

Los moradores de la villa que incumpliendo este artículo tercero eran prendidos con armas y éstas no eran utilizadas ni para protegerse en un viaje, ni para vigilar sus propiedades, eran castigados con la pérdida del arma y además tenían que pagar 60 maravedís. No dice esta condición a qué eran condenados los reincidentes ${ }^{21}$.

La cantidad recaudada por este concepto se repartía entre el alguacil, que tomaba las dos terceras partes, y el resto para el alcalde que juzgaba al infractor. Si durante el proceso el juez determinaba la inexistencia de la infracción y que los hombres del alguacil abusando de su cargo habian cometido una sinrazón éste debía responder por sus hombres, prendiéndoles y llevándoles ante el alcalde para que éste los juzgase. Dictada la pena era el alguacil el que con sus bienes respondía de los maleficios cometidos por sus subordinados.

${ }^{21}$ Las ordenanzas de Ezcaray, de fecha 22 de diciembre de 1465, en su tercera ordenanza nos hablan de las penas por llevar armas: la primera vez, les quitaban el arma; la segunda vez, lo mismo y pagar 60 maravedis, y la tercera vez, lo mismo que la segunda y ocho días en la cadena. Dichas ordenanzas han sido estudiadas por $P$. LONGAS BARTIBAS en su obra Ordenanzas Municipales de Ezcaray. AHDE 31, Madrid 1935. 
Ante la posibilidad de que el alguacil encubriese a sus hombres para no respaldar económicamente sus entuertos se le imponía la pena de perjuro si esto hacia, pena que solía conllevar el ostracismo y, por tanto, el alejamiento del entorno familiar y económico, con la pérdida de bienes e influencias que ello acarreaba.

\section{JURADOS}

El término jurados o «iurati» tuvo diversas acepciones en la Edad Media. Según Valdeavellano los jurados eran los mandatarios del Concejo en los municipios de la España medieval. Otros autores hablan de los jurados como los legítimos representantes del común elegidos para su defensa.

El nombre de jurados, prosigue Valdeavellano, les viene del juramento que prestaban de defender los intereses de la comunidad, siendo elegidos todos los años por el Concejo en número de dos por barrio ${ }^{22}$.

La cuarta condición del cuaderno de 1405 nos habla de los jurados en la villa de Guadalajara y difiere bastante del esquema anteriormente citado.

Los jurados de Guadalajara cumplian las condiciones generales de los oficiales de la villa: ser "contiosos", tener buenas conciencias, ser hombres piadosos y de la villa. Además debían esperar la carta del rey para poder ejercer su oficio pues al igual que el de los regidores tenían la condición de perpetuos ${ }^{23}$.

El número de jurados era de cuatro, uno por cada collación, y una vez elegidos juraban el cargo ante el cabildo de regidores y "quatros", que nuevamente aparecen controlando un relevante oficio concejil.

La función de los jurados era la de actuar en ciertos pleitos concretos que conocemos por las Ordenanzas de 1427, artículos XIV y XV.

${ }^{22}$ L. G. de Valoeavellano, Curso de historia de las instituciones españolas. Madrid 1972, pág. 545.

${ }_{23}$ No debemos perder de vista esta cuestión en extremo interesante. Destaca el trabajo de F. TOMAS y VALIENTE, Origen bajomedieval de la patrimonialización y la enajenación de los oficios públicos en Castilla. Madrid, Actas del I Simposium de Historia de la Administración, 1970, págs. 141 y ss. 
Destacan los referentes a enfrentamientos entre cristiano y moro, o cristiano y judío, pero sólo en aquellos casos en que el judío o el moro era el reo. También debian resolver las apelaciones de los almotacenes, dictaminar sobre las ejecuciones de las rentas de propios del Concejo, portazgos y montes, y realizar las pesquisas acerca de la muerte de alguna persona realizadas bajo las órdenes del alcalde encargado del caso, entre otras funciones de menor importancia ${ }^{24}$.

\section{ANDADORES}

Los andadores o "apparitores» eran los mensajeros del juez en los municipios castellanos medievales. En Guadalajara se conocía también con ese nombre a los hombres que ayudaban a los alcaldes y jurados.

La quinta condición regula su jurisdicción, pero desconocemos su número exacto y su forma de elección.

Los antiguos andadores habian utilizado su principal función, la de tomar prendas a los infractores de las ordenanzas municipales de manera indebida, tomándolas excesivas a los hombres pecheros, que se veian perjudicados por esa actitud ante la enorme dificultad que tenian para recuperarlas. Éstas eran elementos fundamentales de su labor cotidiana: un arado, animales de carga, una huerta, etc. Por eso solicitaba la vecindad de pecheros que los nuevos andadores fueran honrados $y$ que diesen cuenta a sus oficiales de las prendas tomadas para que éstos evitaran los atropellos.

Estos andadores, una vez elegidos, juraban sus cargos ante la asamblea de regidores $y$ «quatros».

\section{IA SENTENCIA DEL ALMIRANTE}

En esta sexta condición hay un punto oscuro: no trata de ningún oficio concejil, sino de una sentencia que dio el Almirante don Diego

\footnotetext{
${ }^{24}$ Noticias del "Libro copiador de ordenanzas y escrituras" de 1545. Signatura 1H52.1.
} 
Hurtado de Mendoza y que el común consideró conveniente recordar en el cuaderno de 1405.

Por medio de este artículo, el común exhorta a los oficiales concejiles, caballeros y escuderos de la villa de Gaudalajara y de su alfoz a que cumplan la sentencia que dio don Diego Hurtado, sentencia que fue elevada hasta el rey y confirmada por los oidores del mismo.

Desconocemos dicha sentencia en su data y en su letra, ya que no hemos hallado noticias referentes a la misma, ni hablan de ella los historiadores de Guadalajara fray Hernando Pecha, Francisco de Torres, Pareja Serrada, Juan Catalina o Layna Serrano.

Con todo pretendemos colegir que dicha sentencia obligaba a la baja nobleza y favorecía a los pecheros por lo cual éstos recordaban a los nobles la obligación de cumplirla.

\section{ALCALDES DE LAS CAÑADAS}

Los alcaldes de las cañadas o alcaldes entregadores de la Mesta están tratados en estas condiciones aunque no eran oficiales del Concejo ni estaban unidos a él bajo ningún aspecto, ya que su misión como oficiales reales destinados en la Mesta consistía en restituir a esta organización ganadera los ganados perdidos o robados para lo cual poseían jurisdicción civil y penal.

Estos oficiales con la excusa de amparar los ganados trashumantes cometían diversas tropelías y creaban todo tipo de altercados con el Concejo, como órgano de poder local, o con los moradores de la villa y de su alfoz, como propietarios de tierras, que presuntamente estaban ocupando el paso de las cañadas ${ }^{25}$.

El común no podía exigir nada a los alcaldes de las cañadas pues estaban protegidos por la poderosa institución ganadera y las amplias surgidas a su amparo.

25 «Los abusos y extralimitaciones de los alcaldes entregadores en su jurisdicción debieron ser tales que los propios monarcas se vieron obligados a prohibir el ejercicio de sus funciones en el concejo y término cacereños". C. MERChán FERnÁndez, obra citada, pág. 41. 
La posición de los pecheros, en su mayoría labradores, quedó reflejada en la séptima condición del cuaderno por medio de una petición de ayuda que realizaban a los nobles como único grupo de poder que se podía enfrentar a los oficiales regios. En ella les piden que tomen la voz con los plebeyos para denunciar los atropellos: "... seades tenudos e obligados de tomar la boz con el dicho común...».

\section{CABALLEROS DE LOS MONTES}

Los caballeros de los montes se escogian entre los caballeros y escuderos de la villa y de su alfoz.

Su función era recorrer los montes del Concejo a caballo vigilando que no se maltrataran éstos para lo cual se ayudaban con unos peones, que nombraban ellos mismos.

El común solicitaba en la octava condición que los caballeros que se escogieran fueran para guardar los montes y no para expoliarlos, vendiendo madera o dejando pastar ganados propiedad de caballeros ajenos al término de la villa.

Propuso el común, para acabar con esto, la pérdida del oficio para el caballero o peón que fuese hallado incumpliendo su deber, recibiendo el peón además la pena corporal de sesenta azotes.

Estos abusos continuarian durante los años posteriores a pesar de las penas llevando a la ciudad a suspender estos oficios en 1475 y a realizar una investigación que dio por resultado que la responsabilidad mayor de la destrucción de los bienes comunales se debía a los guardas de a pie. Ya en el siglo XVI, y en nuevo intento de acabar con estos abusos, la ciudad nombraba a los caballeros de los montes a través de los magistrados ${ }^{26}$.

${ }^{26}$ Caroline Mignot, obra citada, pág. 590. 


\section{ACEPTACIÓN DE LOS OFICIOS}

En la condición novena y final se resume el sentimiento de los pecheros respecto a las anteriores condiciones con la declarada intención del juramento de todas ellas por los destinatarios del cuaderno para dar validez al mismo y como resguardo de derecho.

Los que tras haber jurado incumplieran las condiciones caian en la pena pecuniaria de 2.000 maravedís que eran destinados a los muros, y en la expulsión de la villa.

Exhortaban los autores del cuaderno a los nobles cumplidores de las condiciones para que denunciasen a los infractores y les ayudasen a castigarles.

Los plebeyos tenian conciencia de hallarse en una villa dominada por la baja nobleza protegida por la familia de los Mendoza que tras la victoria trastamarista se había integrado con fuerza en los cuadros de la nueva dinastía.

Indudablemente el triunfo de los Trastámara fue decisivo en el devenir histórico de los grupos sociales de la Baja Edad Media. SánchezAlbornoz dijo al respecto: "Tras el triunfo de la facción enriqueña y nobiliaria después de Montiel (1369), las masas populares tuvieron que sufrir las consecuencias del vencimiento" ${ }^{27}$.

Esto supuso en muchas ciudades el aumento de patrocinio de unas familias de alta nobleza que llegaron a dominar todas las estructuras del poder.

En la villa de Guadalajara los Mendoza fueron señores de hecho ${ }^{28}$, aunque nunca de derecho. A pesar de la guarda de la monarquía, Guadalajara siempre padeció el agobio del tutelaje de esta preponderante familia que llegó a dominar un conjunto de tierras que enlazaba las estribaciones de la Cordillera Central hasta la provincia de Guadalajara.

Esta familia, de procedencia norteña, potenció la llegada de numerosos hidalgos cántabros y vascones que pronto coparon los oficios de la villa y los utilizaron las más de las veces para cohechar y enriquecerse.

${ }^{27}$ Cita de Sánchez-Albomoz, reproducida por Valdeón BARUQUE en su obra citada, pág. 93.

28 «Sólo unas cuantas familias se integraron con firmeza en los cuadros nobiliarios de la nueva dinastía (los Guzmán, Ponce de León, Mendoza, Osorio, Manrique)", Valdeón BARUQUE, obra citada, pág. 97. 


\section{CONCLUSIONES}

1. La primera conclusión es que hubo una injusta gerencia de los oficios concejiles por parte de la oligarquía ciudadana. Lo cual lleva a los habitantes de la villa más perjudicados por dicha gestión, los pecheros, a concretar sus sugerencias y presentarlas en forma de cuaderno.

2. El cuaderno representa el establecimiento del oficio de regidores en la villa de Guadalajara, en 1405 , con una doble función: administradores generales de la hacienda local y garantes de la protección adecuada a los plebeyos frente a las tropelias de la baja nobleza.

3. No nace el Regimiento como una imposición desde arriba. Ni desde la Corona, aun siendo el rey el señor de la villa, ni desde la oligarquía ciudadana que ya detentaba el poder local, sino desde abajo, como idea del común, que intentará asimismo verificar su funcionamiento. Para ello exigen que dos de los ocho regidores sean hombres buenos pecheros. Seis nobles frente a dos plebeyos. Los pecheros salvan esta dificultad numérica colocando a los "quatro", delegados de los barrios, junto con los regidores en un cabildo que se encargará del control de los juramentos para ejercer los oficios concejiles. En el instante del juramento el cabildo es paritario, seis regidores elegidos entre caballeros y escuderos quedan compensados por dos regidores de los pecheros, más los "quatro".

Con esta fiscalización, los pecheros no perdían de vista un momento trascendental en el proceso de elección de oficiales locales: el juramento.

4. Como hemos visto, una de las puntas de lanza del ataque defensivo del común son los "quatro". Éstos aparecen con frecuencia en sesiones del Concejo y participando en la supervisión de las cuentas que realizan los oficiales. Su consecuente intervención como representantes de las collaciones contrasta con la de los sexmeros que apenas ejercitan su condominio como comisionados de los sexmos del alfoz y no participan en las tomas de decisión ni en el control efectivo de la administración municipal.

5. Inferimos que todos los caballeros y escuderos de Guadalajara y su término fueron jurando el cuaderno paulatinamente sin que pusieran inconvenientes en realizar este acto. Tampoco parece que se tomaran muy en serio las condiciones del mismo ni el juramento pese a las penas indicadas para los contraventores del articulado, pues en las Ordenanzas de 1427 nos encontramos muchas de las reivindicaciones del común 
como algo no conseguido: andadores que toman prendas excesivas, jurados que no conocen su jurisdicción, caballeros que incumplen normas, etcétera.

Es evidente que la vida de la villa cambió con la aceptación del cuaderno por el patriciado urbano, al menos de momento después volvieron los excesos y el siguiente ordenamiento local, el de 1427, se hizo bajo la supervisión de un corregidor real, Juan de San Andrés ${ }^{29}$.

Aun a riesgo de contradecir a Caroline Mignot, que en su citado artículo "Le "Municipio" de Guadalajara au XV $\mathrm{v}^{\text {eme }}$ siècle..." se inclina por la llegada al poder de una oligarquía de caballeros ${ }^{30}$, podemos afirmar que el cuaderno de 1405 fue un triunfo del común, prueba de la resistencia frente a la oligarquía.

El nacimiento del Regimiento llega con la complacencia de los pecheros pero ese triunfo fue efímero. En 1427 el común de Guadalajara ha perdido la batalla de la vigilancia de la administración, único medio de no seguir siendo víctima de los desmanes del patriciado urbano. Las ordenanzas de ese año señalan el fin de una utopia; la administración volvió a partir de entonces a manos de la nobleza para posteriormente caer, como fruta madura, en manos de una Corona fuertemente ordenancista como lo fue la de los Reyes Católicos.

6. Con qué fuerza contaba el común es algo que no hemos podido precisar. ¿Hubo un aviso de rebelión? Es probable, porque, si no, ¿de que otro modo podrían cumplir su amenaza de arrebatar los oficios a los caballeros y escuderos si éstos no aceptaban las condiciones? Consideramos pues, a modo de conclusión final, que el mayor triunfo del común en 1405 no residió en poner las mencionadas condiciones a caballeros y escuderos sino que éstos las jurasen.

29 En dichas ordenanzas leemos “... estando ende el bachiller lohan de Sant Andres corregidor e justiçia de la dicha villa e su tierra por nuestro señor el rey". Libro copiador de ordenanzas y escrituras, 1545.

3o Caroline MignOT, aun partiendo de los mismos supuestos, llega a un resultado final bien distinto, el triunfo de la oligarquía urbana: «... que rédigent les seuls citadins roturiers elle met fin aux discordes pour l'exercice du pouvoir et marque l'avenement d'une oligarchie de chevaliers", obra citada, pág. 583. 


\section{APÉNDICE DOCUMENTAL}

El documento $n^{\circ}$ I, es un tralado acta de 1417 del cuaderno de condiciones del común de 1405, conservado en el AMGU (Archivo Municipal de Guadalajara),

El $n .^{\circ}$ II, es un traslado de 1417 del acta de juramento por la señal de la Cruz realizado por escuderos de la villa de Guadalajara el 3 de noviembre de 1405 . Este segundo documento pretendemos sirva de ejemplo de los juramentos de carácter religioso. También conservado en el AMGU 1H3.8b.

El n. ${ }^{\circ}$ III, es un traslado de 1417 del acta de aceptación del cuaderno de condiciones y en el que caballeros y escuderos se obligan por sus bienes, con fecha 29 de octubre de 1405. AMGU $1 \mathrm{H} 3.8 \mathrm{~b}$.

a) Grafías

1) Se ha respetado la grafía de los documentos originales.

2) Los errores evidentes del escriba se han respetado, subsanándolos en notas al final del documento y colocando las llamadas entre (), porque nos ha parecido lógico conservar las irregularidades de los documentos originales.

3) El único error de repetición de palabras ha sido señalado mediante (sic).

4) Las letras, palabra o frases ilegibles, por rotura del documento original, se han suplido, en parte, acudiendo al traslado de 1545, y señalándolas entre [], y en parte, con fragmentos de carácter conjetural, y acercándonos lo más posible al sentido del texto, éstas se han colocado entre \{\} . 
b) Abreviaturas

1) Todas las palabras abreviadas se han desarrollado sin señalar las letras suplidas.

c) Uso de mayúsculas

1) Se ha seguido la costumbre moderna para nombres de personas y topónimos.

2) Se han escrito con mayúscula los nombre de Dios, la Cruz y los Santos Evangelios.

d) Puntuación

1) Se ha seguido el sistema moderno de puntuación, aunque en los documentos II y III se ha evitado la colocación de puntos y aparte que rompieran la estructura del manuscrito original.

e) Escritos dorsales

1) Sólo hemos reproducido las notas que figuran en la cabecera del primer folio recto del traslado acta del cuaderno de condiciones, numerándolas como nota (1). 


\section{DOCUMENTO N. 1}

1417, septiembre, 10. Guadalajara.

Traslado del cuaderno de condiciones del común de la villa de Guadalajara a los caballeros y escuderos de 28 de octubre de 1405.

AMGU 1H3.8a

Edit. Layna Serrano: Historia de Guadalajara y sus Mendoza en los siglos XV y XVI, t. II, págs. 519 a 522, CSIC, Instituto "Jerónimo Zurita». Madrid 1942. (Versión del Libro Copiador de 1545.)

(Ordenanzas de la villa del tiempo que no avia regidores en ella) ${ }^{1}$.

En Guadalfajara, diez dias de setienbre, año del nasçimiento del nuestro Salvador Ihesu Christo de mill e quatroçientos diez a siete años, este día, ante Gutier Nuñez, liçençiado, alcalde en la dicha villa e en presençia de mi, Pero Ferrández, escrivano público en la dicha villa e de los testigos de yuso escriptos, paresçieron y presentes, Sancho Diaz de Cor[ti]nas e Ruy Ximénez Cherino e Juan de Enzinas, vezinos de la dicha villa e pr[esen]taron e leer fizieron por mi el dicho escrivano antel dicho alcalde un quaderno de es[criptura] escripto en papel signado e firmado de escrivano, segund que por el paresçia, el thenor del cual es este que se sigue:

En la iglesia de Sant Gil[1] de Guadalfajara, veinte e ocho dias del mes de otubre, año del Nasçimiento [de] nuestro Salvador Ihesu Christo de mill e quatrocientos e cinco años; este dicho d[ia] estando en la dicha iglesia el comun e omes buenos pecheros e quatros e sexmeros de la dicha villa de Guadalfajara e de su tierra,

\footnotetext{
'Escrito también en letra cortesana, pero por distinto escribano.
} 
ayuntados e llamados por canpana rrepicada, segund que lo han de uso e de costunbre de se ayuntar, e estando y presentes, Diego Ferrández de Hita, texedor, quatro de la collaçión de Santiago, e Diego García, fijo de Benito García, quatro de la collaçión de Sant G[il], e Gonçalo Ferrández, criado de Sancho Sánchez, quatro de la collaçión de Sant Nicolas, e Pero Ferrández, carralero, quatro de la collaçión de Santa María de la dicha villa, [e] Lucas Martínez, vezino de Taraçena, sexmero del sexmo de Albolleque, e Juan Martínez d[el] Exido, vezino de Valfermoso, sexmero del sexmo de Valdavellano e D[ie]go Ferrández, fijo de Diego Ferrández, vezino de Renera, sexmero del sexmo de Taran[çena] ${ }^{2}$ e Diego Ferrández de S[ill]as, vezino de Hontanar, sexmero del sexmo de Málaga, [al]deas e tér[mino] de la dicha villa, e en presençia de mí, Juan Sánchez de Coca, escri[vano] [público] de la dicha villa Juan [Martínez], fijo de [Alonso Martínez] de Fuente Enzina, vezino otrosi de la dicha villa e procurador [que] se mostró ser e es del dicho común e omes buenos pecheros de la dicha villa [de] [Guadalfajara] e de su tierra; e luego el dicho Juan Martinez presentó e fizo leer por [mi] el dicho [escrivano], en presencia del dicho común e omes buenos e quatros sexmeros de la dicha villa e de su tierra un quaderno de condiçiones escrip[to] en papel [el thenor del qual] es este que se sigue:

Señores, [cavalleros], escuderos de la villa de Gua[dalfajara], estas [son las condi]çiones que[los quatros y los homes buenos pecheros] de las collaçiones [de la] [dicha] villa de Gua[dalfajara], por nos mismos e en] nombre [del común de la dicha villa de Guadalfaja]ra, vos pedimos que nos guardedes e fagades guardar e conplir por que todos seamos concordados e amigos conjuntamente con vosotros en rrazón de los ofiçios [por] que entendemos que asi cunple a serviçio de Dios e de nuestro señor el rey [e] [po]blamiento de la dicha villa e de su tierra; e son estas que se siguen:

(1) [Primer]amente que luego que sean tomados por parte de vos, los dichos cavalleros e [esc]uderos, seis omes buenos para rregidores, para ver fazienda del conçejo [de la] dicha villa. E estos

2 Posiblemente el escribano quiso referirse a la aldea de Taraçena, a las afueras de la villa de Guadalajara. 
dichos seis rregidores que sean tales que teman [sus] ánimas e guarden servicio de nuestro señor el rey e poblamiento de la dicha [vil]la, estando juntamente com ellos, dos omes buenos rregidores, por parte [de I]os dichos omes buenos pecheros de la dicha villa e su tierra a estos [di]chos ocho regidores que sean para rregir la dicha villa e para que desa[gravien] los agravios que fueron fechos por los alcaldes e ofiçiales e otros quales[qui]er que sea fecho o fechos, e que estos dichos ocho rregidores [que ansi] fueren tomados e escogidos que non puedan usar del dicho rregimiento [sin] carta del dicho señor rey, por quanto son ofiçios perpetuos faziendo ju[ra]mento al dicho señor rrey de tener e guardar e mantener en paz e en jus[ti]çia e en buen rregimiento la dicha villa e su tierra. $E$ que estos dichos o[cho rre]gidores que puedan poner e pongan mayordomo e mayordomos para [que puedan cobrar e] recabdar los propios de la dicha villa para que se desprendan [e] gasten de cada año los dichos propios en los muros de la dicha v[vill]a por quanto fueron estableçidos para los dichos muros por escu[sar c]ostas e daños e perdimiento de lavores de los dichos la[br]adores e [omes] buenos pecheros de la dicha villa e de su tierra, lo qual señores vosostros, [bien sabe]des que fueron establesçidos para lo que dicho es. Et por ende si el [tal] mayordomo o mayordomos tomados por los dichos regidores non [fuer]en tal o tales que sean contiosos por que los dichos [propios] este a [buen re]cabdo para los despender en los dichos muros de la dicha villa $\mathrm{p}$ [or man]damiento de los dichos rregidores e non en otras cosas ni en otras partes [sal]vo si el dicho señor rrey lo enbiare mandar por [su] carta espaçifi[ca]damente, en qué e para qué, que los dichos rregidores sean [te]nudos e oblig[ados de lo pagar por] ellos e [por] sus bierıes [e demás e que sean ten]udos los dichos [rregidores de fazer, de mudar e traspasar los dichos mayo]rdomos con ca[da uno de ellos la dicha] mayor[domía de dos en dos años, e] de unas pers[onas en] otras e que den cuenta de cada año a los dichos rregidores estando y ante ellos [conjunt]amente los dichos quatros que fueron a la sazón en la dicha villa, esto se [ent]ienda, pagando el salario de los dichos rregidores que son quatro mill maravedís.

(II) Otrosi que los que ovieren de echar suertes por los ofiçios de las alcaldias de la [ju]stiçia ordinaria que sean tales et pertenesçientes e contiosos e omes [de] buenas conçiençias e que teman sus animas e guarden serviçio del dicho señor rrey et tengan en justiçia e todos igualmente segund cunple en [t]al caso; e los que asi fueren tomados e escogidos para echar las dichas suertes, que 
despues de echadas las dichas suertes que a los que cayeren las dichas alcaldias que fagan juramento segund forma de derecho que bien e verdaderamente guardaran todo lo sobredicho. E quel dicho juramento, lo fagan en la iglesia de San Gil de la dicha villa en cada un año [est]ando presentes los dichos rregidores e los quatros de las dichas colla[ci]ones e por ante escrivano público porque los dichos rregidores e quatros [e] cada uno de ell[os] lo tomen por testimonio para guarda de la dicha villa e [su] tierra.

(III) [Otro]si que ningund cavallero ni escudero ni omes suyos nin otra persona al[guna] non puedan traer armas nin arma alguna nin algunas por la dicha vi[lla], salvo si fuere en camino fuera de la dicha villa e a las vi[ñas] o a sus heredades, salvo el alguazil et el su logarteniente e sus [omes] so pena de sesenta maravedis, terçiados, las dos partes para el alguazil e la [ter]çera parte para el alcalde que lo judgare e le tomen el arma; e estos omes [a] tales que el el dicho alguazil tomare que sean nonbrados quales e quantos son ante los dichos rregidores de la dicha villa; por que si alguna cosa feziere non devida por los tales omes, por él o logarteniente, que el [di]cho alguazil sea tenudo de lo pagar por si e por sus bienes e de traer el tal ome o omes quel tal maleficio fizieren ante los dichos alcaldes 0 ante qualquier de ellos seyendo requerido el dicho alguazil por los dichos ofiçiales por qualquier de ellos que del tal ome o omes que fizieren el dicho malefiçio si lo ovieren o fueren en su poder para que ellos manden fazer [de el o de ellos lo] que fallaren por derecho. Et esto que lo faga [el dicho] alguazil [so pena de perju]ro; e esto que sea si lo pudieren aver al tal [ome o omes] e [non fagan de] ello arte nin engaño e si le fuere pro[vado caya] en la dicha pena de perjuro e en razón del traher de las dichas arm[as] si alguno los troxiere que non caya en la pena de perjuro si non que pase [por] las penas contenidas en esta dicha ley de los dichos sesenta maravedis e que [le] sea tomada el arma.

(IV) Otrosi por quanto fue uso e costunbre de luengo tienpo aca de aver jurados [para] conosçer de çiertos plitos segund que suelen conosçer de derecho en los [di]chos tienpos pasados; e que estos jurados que non sean más de quatro e [que] sean tales que convengan e contiosos e de buenas conçiençias porque a[nsi] cunple a serviçio de Dios e del dicho señor rrey e poblamiento de la [di]cha villa e su tierra; e que estos dichos jurados que asi fueren esco[gi]dos que non puedan usar de los dichos ofiçios fasta que 
ayan carta de [man]damiento del dicho señor rey, por quanto son ofiçios perpetuos e fagan [el] dicho juramento ante los sobredichos rregidores e quatros por ante el [dicho] escrivano por que los tomen por testimonio como dicho es.

(V) Otrosi por quanto en los tienpos pasados, los alcaldes e j[ur]ados ponian andadores tales que non convenyan por lo qual venia muy grand [mal] e daño a los omes buenos pecheros de la dicha villa e su tierra [e] levavan más de lo que devian levar de derecho e las prendas que [te]nian que non las podian cobrar sus dueños e otras cosas muchas [que] fazian non buenas que los tales alcaldes e jurados e alguazil que [pongan] e tengan tales andadores que sean buenos omes de verdad e de buena [cu] enta de las prendas e entregas que fizieren o non fagan otras syn raz[ones] algunas, salvo que leven su derecho e que los dichos andadores que asi fu[eren] tomados por los dichos ofiçiales para fazer las dichas entregas e cobr[ar] sus derechos, que fagan juramento segund forma de derecho ante los [di]chos regidores e quatros que bien e verdaderamente usaran de la dicha andaduria, so peligro del e de sus bienes; e si lo contrario fizieren los dichos ofiçiales, alcaldes e jurados e alguazil, sean tenudos a por [fa]zer el daño o el mal que viniere a cada uno por el su andador por quanto es asi derecho e rrazón.

(VI) [Otrosi] que los dichos regidores e alcaldes e jurados e ca[v]alleros e escu[deros e cada] uno de ellos, todos en general e cada [uno en espe]çial que [seades] tenudos e obligados de guardar e co[nplir la sentençia] que el almirante don Diego Furtado de Mendoça dió, la qual confirmada por los oidores del dicho señor rey, en grado de vista e de revista entre vos los dichos ofiçiales e escuderos e cavalleros de alarde e el dicho común segund e en la manera e forma que en ella se contiene; e que nunca ires ni verrieis contra (sic) ella nin contra parte de ella agora nin de aqui adelante por la desatar nin menguar en tal manera que la dicha sentençia quede en su virtud.

(VII) Otrosí por quanto acaesçe que el alcalde de las cañadas e caros ${ }^{3}$ algunos por el vienen algunas vezes e otras personas qualesquier que sean en qualquier manera por rrazón de toma de

3 Creemos que el escribano quiso poner "pasos" y no "caros". 
término e dizen por cohechar a los vezinos de la dicha villa e su tierra, diziendo que van cañadas por casas o por viñas e por faças de tierras e fazen prendas e enplaçamientos non devidos a los dichos pecheros por ende que los dichos rregidores e alcaldes e cavalleros e escuderos que seades tenudos e obligados de tomar la boz con el dicho común e de los ayudar e anparar a derecho, ellos a vos e vos a ellos, de las tales personas que las tales [s]inrazón quisieren fazer, por quanto es serviçio del dicho señor rey $[e]$ poblamiento de la dicha villa e su tierra.

(VIII) [O]trosi por quanto entre vosotros sacades cavalleros de los montes de la dicha [v]illa para guarda de ellos que los tales cavalleros que ponen sus peones [par]a ello e los tales peones venden los montes en diversas maneras [an]sí para [los ganados] como para quemar, así a los del término como a los de [fu]era del. [E otrosí] que los cavalleros que abienen con los de fuera del término para que pastan sus ganados e bevan las aguas en término de la dicha villa. Por ende que los tales cavalleros e peones que tal fizieren, que pierdan el ofiçio, el cavallero, e el peón que le den sesenta a[ço]tes por ello e nunca aya más los tales ofiçios.

(IX) Otrosi que los dichos regidores e cavalleros e escuderos e alcaldes e jurados, que fagades aparte provisión de juramento valedero de te[mer] e guardar e conplir todas las cosas e condiçiones suso dichas e [c]ada una de ellas, agora e de aqui adelante e qualquier o qualesquier que vi[ni]eren o vini[esen] contra las dichas condiçiones o contra alguna de ellas que [c]ayades e [cayan cada ujno en pena de dos mill maravedis e más que sea avido por perjuro e que los otros de vos los sobredichos que perseverarades en guardar los [sobre] dichos e que seades tenudos e obligados de tomar la boz con el dicho común e omes buenos pecheros e quatros e sexmeros de la dicha villa e su tierra e de los ayudar contra tales los trasguesores para los punir por la dicha pena de los dichos dos mill maravedis e fazer execuçion della en sus bienes del o dellos e que la tal pena que sea para los muros de la dicha villa e qualquier o qualesquier que esto non quisieredes guardar e conplir que ayades e seades avidos por en la dicha pena de perjuro ${ }^{4}$.

4 A partir de aqui el texto es inédito. 
El qual dicho quaderno de condiçiones presentado e leydo en la manera que \{di\}cha es, luego el dicho Juan Martinez dixo al dicho común e omes buenos \{pe\}cheros que y estavan presentes que si los dichos cavalleros e escuderos de la dicha villa les guardasen e toviesen e conpliesen e $\{\mathrm{fi}\}$ ziesen juramento de tener $\mathrm{e}$ guardar e conplir las dichas condiçiones como en ellas se contenía e so las penas en ellas contenidas que $\{a\}$ ellos se plazía e consentía que los dichos cavalleros e escuderos que ayan e oviesen los dichos sus ofiçios segund que senpre los \{tovi\}eran que así lo dixiesen e declarasen luego de presente. $E$ luego el dicho común e omes buenos pecheros e quatros e sexmeros de la di\{cha\} villa e su tierra, en respondiendo, dixeron que por quanto entendían que el di $\{c h o\}$ quaderno de condiçiones e los capitulos en él contenidos que eran bien $\{\mathrm{fe}\}$ chos e ordenados así a serviçio de Dios e del dicho señor rrey como a pro e honrra de la dicha villa e su tierra e de los omes bu\{enos\} pecheros que en la dicha villa e su tierra vivian, por ende dixeron \{que si\} los dichos cavalleros e escuderos guardando e conpliendo e tenien $\{$ do $\}$ e faziendo juramento de tener e guardar e conplir todas las di[chas] condiçiones e capítulos contenidos en el dicho quaderno asi en gene $\{\mathrm{ral}\}$ como en espeçial que a ellos plazia e eran plazenteros e consentí\{an\} e eran consentidores que los dichos cavalleros e escuderos que ayan e cobren los dichos sus ofiçios segund que sienpre los ovieran de la dicha villa e dixeron que guardando e conpliendo todo lo que dicho es, que davan e dieron poder conplido bastante espeçialmen[te\} para en este caso al dicho Juan Martínez, su procurador \{que\} y estava pre \{sente\} para que con el procurador de los dichos cavalleros e \{escuder\}os de la dic\{ha villa\} más firme fizieron juramento en la senal de la cruz e las palabras de los santos evangelios que tanxieron con sus manos corporalmente segund forma de derecho que a todo su poderio que ternán e guardarán e conplirán las dichas condiçiones e capitulos de la forma e manera que en ellas e en cada una dellas se contiene so penas de perjuros. Que fueron testigos presentes a esto Juan Martinez de Fuente Enzina, e Alfonso Ferrández de Brihuega e Juan de Aguilar, vezinos de Guadalfajara. Va testada una parte en un logar, e escripto entre reglas o dize: "Quintanilla", e sobrerraydo o dize: "de la dicha"; e entre renglones o dize: "so pena de perjuros segund que en las dichas condiçiones se contiene", e sobrerraydo o dize: "dixo que por rrazón que él»; e en otro logar entre reglas o dize: "so pena de perjuro"; e en otro logar o dize: «E Pero Garçia fijo de Pero Garçía de Trillo"; e sobrerraydo o dize: "de la dicha»; e sobrerraydo o 
dize: «forma». Vala e non lo enpesca. E yo Juan Sánchez de Coca, escrivano público de Guadalfajara sobredicho fui presente a todo lo sobredicho con los dichos testigos e a otorgamiento de los contenidos este dicho juramento esta escriptura fiz escribir en siete fojas de papel con esta en que va mi signo e en fin de cada foja de amas partes van firmadas de mi nombre e so ende testigo e en testimonio de verdad fiz aqui este mio signo. 


\section{DOCUMENTO N. ${ }^{\circ} 2$}

1417, septiembre.

Traslado del acta del juramento, de 3 de noviembre de 1405 , dado por escuderos de la villa de Guadalajara, por la señal de la cruz, aceptando el cuaderno de condiciones del común de la dicha villa.

AMGU $1 \mathrm{H} 3.8 \mathrm{~b}$.

E despues desto, tres dias del mes de novienbre año sobre dicho, e en presençia de mi el dicho escrivano e de los testigos yuso escriptos parescieron y presentes: Pero Páez, fijo de Ferrando Páez e Ruy Ximénez Cherino e Diego Ferrández de la Fuente, vecinos de la dicha villa Guadalfajara; e luego, estos sobre dichos escuderos dixeron: que sobre rrasón que ellos por ante mi el dicho escrivano se avian obligado e estavan obligados a tener e guardar e conplyr las dichas condiçiones e capitulos en este quaderno contenidas e so las penas en ellas contenidas, segund que por ante mi el dicho escrivano avía pasado, por ende dixeron: que por que mejor e más conplidamente lo ellos toviesen e guardasen e cunpliesen e por mayor abondamiento de derecho fizieron juramento en la señal de la Cruz e las palabras de los Santos Evangelios, que tanxeron con sus manos corporalmente, segund forma de derecho de tener e guardar e conplir las dichas condiçiones e capitulos de la forma e manera que en ellas e en cada una dellas se contiene so pena de perjuros, segund que en las dichas condiçiones se contiene. Que fueron testigos presentes a esto: Diego Ferrández de Mendoça e Ferrando Páez de Çorita e Juan Ferrández de la Fuente e Ferrando López de Horozco e Ruy Lorenso, vezinos de Guadaliajara. 


\section{DOCUMENTO N. ${ }^{\circ} 3$}

1417, septiembre.

Traslado del acta de juramento, de 29 de octubre de 1405, dado por caballeros y escuderos de la villa de Guadalajara, aceptando el cuaderno de condiciones del común.

AMGU 1H3.8b.

E esto, fecho luego este dicho día en la cámara del Conçejo de la dicha villa Guadalfajara, estando en la dicha cámara el concejo, cavalleros, escuderos e omes buenos de la dicha villa, ayuntados e llamados por canpana rrepicada segund que lo han de uso e de costunbre de se ayuntar e estando y presentes Ferrando Páez, cavallero, e García López fijo de García López de Trillo, e Lope García de Salazar, e Ferrando Mexía, e Ruy Lorenço fijo de Lorenço Páez, e Juan Gastón fijo de Ferrando Gastón, e Ferrando López de Horozco, e Ferrando Páez de Çorita, e Garcia López fijo de Lorenço Ruiz de Trillo e Sancho Ferrández el tio, e Ruy Sánchez de Horozco, e Miguel Ruiz de Benegas, e Diego López de San Pedro e Juan Ferrández de Ribera, vezinos de la dicha villa Guadalfajara.

Otrosi estando y presentes los dichos quatros e sexmeros de la dicha villa e su tierra e en presençia de mi el dicho Juan Sánchez, escrivano e de los testigos yuso escriptos paresçio y presente el dicho Juan Martínez, procurador sobredicho, fizo leer por mi el dicho escrivano, en persona de los sobredichos cavalleros e escuderos, el dicho quaderno de condiçiones e capítulos e asi leydo por mi el dicho escrivano, luego el dicho Juan Martínez, en el dicho nombre de la dicha villa e del dicho común pidió a los dichos cavalleros e escuderos que y estavan presentes, que tengan e guarden e cunplan las condiçiones e capítulos, segund que en ellas e en cada una dellas se contiene fasiendo el dicho juramento de lo asi tener e guardar e conplir, so las penas contenidas en el dicho 
quaderno segund dicho avía. E luego los dichos cavalleros e escuderos que y estavan presentes en rrespondimiento dixeron que, veyendo que las dichas condiçiones e capítulos que eran bien fechas a serviçio de Dios e del dicho señor rrey e a pro e honrra de la dicha villa e de su tierra e de todos los vezinos e moradores que en ella bivian, e dixeron todos los dichos cavalleros e escuderos que y estavan presentes que los plazia de tener e guardar e conplir las dichas condiçiones e capítulos e todo lo en ellas contenido, asi en general, como en espeçial e dixeron que se obligaban e obligaron de tener e conplir las dichas condiçiones e capítulos e de non yr contra ellas, nin contra parte dellas en juysio nin fuera de juysio, por las desatar nin menguar en ningund tienpo por alguna manera e rrazón que sea o ser pueda, so las penas contenidas en las dichas condiçiones e capitulos, e dixeron que para lo asi tener e guardar e conplir e pagar las dichas penas si en ellas cayesen que obligavan e obligaron a ellos e a todos sus bienes por lo doquier que los ellos ovieren. E desto en como pasó, los dichos quatros e sexmeros pidieron a mi el dicho escrivano que ge lo diese signado \{de\} mi signo para guarda de su derecho. Fecho en dia, mes e año sobredicho, que fueron testigos presentes de esto: Ruy Ximénez Cherino e Juan de Horozco, fijo de Diego Ferrández e Ferrando Díaz de Villa Real e Pero Ferrández, criado de Ferrando Díaz Dahe e Esteban Sánchez de la Celada e Alfonso Ferrández de Brihuega e Juan Ferrández Delicado e Pero Martínez de Quintanilla, vezinos de Guadalfajara. 